\title{
Glucocorticoid-induced osteoporosis: 2013 update
}

\author{
M. Mazzantini, O. Di Munno \\ Rheumatology Unit, Department of Clinical and Experimental Medicine, University of Pisa, Italy
}

\begin{abstract}
SUMMARY
Glucocorticoids are the most common cause of secondary osteoporosis leading to the so-called glucocorticoidinduced osteoporosis (GIO). A treatment with $10 \mathrm{mg} / \mathrm{d}$ of prednisone or equivalent for more than 3 months leads to a 7 -fold increase in hip fractures and a 17 -fold increase in vertebral fractures. The difference between bone quantity and quality in GIO makes bone mineral density measurements inadequate to detect patients at risk of fracture. The adverse effects of glucocorticoids on the skeleton derive from a direct impact on bone cells with a severe impairment of mechanical competence. Crucial to prevention of GIO is early timing of intervention. The World Health Organization has adopted a fracture prevention algorithm (FRAX) intended to estimate fracture risk in GIO. The American College of Rhematology modified its prevention and treatment guidelines taking into account the individual risk of fracture calculated in GIO on the basis of the FRAX algorithm. Recently, also a joint Guideline Working Group of the International Osteoporosis Foundation (IOF) and the European Calcified Tissue Society (ECTS) published a framework for the development of national guidelines for the management of GIO. Bisphosphonates are the first-line drugs to treat GIO; teriparatide counteracts several fundamental pathophysiologic aspects of GIO; denosumab is useful in patients with renal failure and in potentially pregnant young women. Vertebroplasty and kyphoplasty may be less beneficial in GIO than in primary involutional osteoporosis.
\end{abstract}

Key words: Glucocorticoid-induced osteoporosis.

Reumatismo, 2014; 66 (2): 144-152

\section{EPIDEMIOLOGY}

lucocorticoids (GCs) are very frequently used in the long-term treatment of patients with chronic diseases, such as rheumatoid arthritis, polymyalgia rheumatica, connective tissue diseases, inflammatory bowel disease, and chronic obstructive pulmonary disease.

A retrospective study showed that more than $80 \%$ of 365 rheumatoid patients followed for at least 10 years continuously in a single center (mean follow up 14.2 \pm 4.0 years) have taken GCs with a mean duration of exposure of 8 years (1). It has also been estimated that about $3 \%$ of the population aged 50 years or older has used GCs. This percentage climbs to $5.2 \%$ among over 80 s or older patients (2).

Corresponding author:

Maurizio Mazzantini

Rheumatology Unit

Department of Clinical

and Experimental Medicine

University of Pisa, Italy

E-mail: mmazzant@int.med.unipi.it
Long-term glucocorticoid treatment, even at low doses $(\leq 7.5 \mathrm{mg}$ of prednisolone or equivalent), rapidly induces bone loss and increased risk of vertebral and non-verte- bral fractures (3). Bone loss is more marked in the trabecular bone and starts soon after the initiation of therapy $(3,4)$ with a steep increase in vertebral and ribs fractures. The GC-induced bone loss unfolds over 2 phases: a rapid initial phase with a 3-5\% loss in the first year of GC treatment and a subsequent slower phase with continued use and a $0.5-1 \%$ loss annually $(5,6)$.

Furthermore, GC use increases the risk of all fractures in a dose-dependent manner $(7,8)$ and is associated with a particularly high risk of vertebral fractures (2-5 times, depending on the daily dosage of prednisone).

The increase in fractures already occurs 3 months after treatment has started (9). In GC-induced osteoporosis there is a weak correlation between bone density (BMD) and fracture risk.

Besides bone loss, the risk of fracture is also increased by a reduced bone quality (10). 


\section{PATHOGENESIS}

The pathogenesis of GC-induced osteoporosis (GIO) is complex and involves both skeletal and extra-skeletal events. Earlier views on its pathogenesis stressed the extra-skeletal effects of GCs, such as a decrease in intestinal calcium absorption and an increase in renal calcium excretion (1114). Calcium absorption from the gastrointestinal tract is inhibited by mechanisms that counter the action of vitamin D (15). It is also known that not only does prednisone increase the catabolism of $25(\mathrm{OH})$ D (16-18), but it may induce a significant weight gain.

On the long-term, this may compound the negative effects of GCs on vitamin $D$, which is soluble in fat and becomes less bioavailable $(15,19)$. As a consequence, secondary hyperparathyroidism may develop, even though several studies found normal parathyroid hormone levels in patients who follow a long-term GC treatment. Furthermore bone histomorphometric features indicate that secondary hyperparathyroidism does not play a key role in the pathogenesis of the bone disorders observed in GIO (12, 20). Exogenous GCs also decrease the secretion of adrenal androgens and estrogens (21), which is associated with changes in the growth hormone-insulin-like growth factor 1 (GH-IGF1) axis and insulin production $(22,23)$.

GH secretion is blunted by $\operatorname{GCs}(24,25)$ mainly by an increased hypothalamic somatostatin tone. GCs also decrease IGF-I transcription in osteoblasts (26). Although hypogonadism, reduced production of IGF-I and increased losses of calcium from the kidney and intestine significantly contribute to GIO, the main sources of skeletal damage during a GC treatment are considered to be the direct effects on all cell types $(11,12,14,27)$.

At the cellular level, the most marked effect of GCs is a decrease in osteoblastogenesis due to inhibition of the Wnt $\beta$-catenin signaling pathway and an increase in osteoblast apoptosis due to the activation of caspase $3(28,29)$, resulting in decreased bone formation $(11,12,14)$. The impairment of the osteoblast differentiation of the bone marrow stromal cells is accompanied by a shift towards the adipocytic lineage due to a decrease in bone morphogenetic protein-2 and a repression of runt related protein 2 (Runx2) associated with an increase in peroxisome proliferator-activated receptor $\gamma 2$ (PPAR $\gamma 2)$ and in CAAT enhancerbinding proteins $(12,14,30,31)$.

The inhibition of the Wnt $\beta$-catenin pathway has emerged as a key mechanism underlying reduced bone formation $(32,33)$. In bone metabolism, the Wnt signal plays a pivotal role in osteoblastogenesis (34). This pathway is negatively regulated by dickkopf-1 (Dkk-1) and sclerostin. GCs lead to an upregulated expression of these inhibitors (35-27), thereby suppressing the binding of Wnt to low-density lipoprotein receptor-related proteins 5 and 6 (LPR5/$6)$. This leads to a reduced ability to stabilize $\beta$-catenin and to the inhibition of bone formation by blocking the transcription of target genes (38).

Emerging data also suggest an additional pathogenic event in the significant decrease of bone formation associated with GCs. Decreased osteoblastogenesis might also be due to the attenuation of the serine/ threonine kinase Akt activity and Forkhead box $\mathrm{O}$ (FoxO)-mediated inhibition of Wnt signaling, as well as increased osteoblast apoptosis, which might also result from an increase in reactive oxygen species (ROS) and activation of the ROS/ PKC_/p66she/ JNK cascade (39-41).

In animal and in vitro studies GCs increased ROS and the phosphorylation of p66shc (an amplifier of $\mathrm{H} 2 \mathrm{O} 2$ generation in mitochondria) in osteoblasts (39). Consequently the generation of ROS via PKC_/ p66shc signaling converts oxidative signals into apoptosis of osteoblasts $(39,40)$. The increase of ROS is also responsible for the activation of FoxO transcription factors expressed in bone cells, which play a critical role in bone homeostasis (40).

As a result of the suppressed Akt activity by GCs (39), ROS promote FoxO binding to $\beta$-catenin and thereby divert $\beta$-catenin from TCF- to FoxO-mediated transcription causing a decrease in osteoblastogen- 
esis (39-41). The activation of caspase 3 , a common downstream effector of several apoptotic signaling pathways $(28,29)$ in response to GCs also results in increased apoptosis of osteocytes $(12,14,27,42)$. Osteocytes function as mechanosensors and their interlacing dendrites form a network of channels transmitting information to the bone surface $(42,43)$.

The loss of osteocytes might be particularly important for the bone structure, because this mechanosensor is important in the repair of bone microdamage $(42,43)$. Disruption of the osteocyte-canalicular network, because of osteocyte apoptosis, results in a failure to detect signals that normally stimulate the replacement of the damaged bone (44) and could adversely affect the material properties of the surrounding bone, independently of changes in bone remodeling or architecture.

Additionally, the increased osteocyte apoptosis is associated with a decrease in vascular endothelial growth factor and skeletal angiogenesis (45). Therefore the effect of GCs on osteocytes might account for a disproportionate loss of bone strength in relation to the bone mass.

In contrast to osteoblastogenesis, osteoclastogenesis is actually promoted by the use of GCs, which increase the expression of M-CSF and RANK-L, and decrease the expression of its soluble decoy receptor, osteoprotegerin, in stromal and osteoblastic cells $(14,46,47)$. GCs also enhance the expression of interleukin-6, an osteoclastogenic cytokine, and suppress the expression of interferon- $\beta$, an inhibitor of osteoclastogenesis $(48,49)$. In accordance with their effects on bone resorption, GCs enhance the expression of selected matrix metalloproteinases (MMP).

Osteoblasts secrete MMP1 or collagenase 1 and MMP13 or collagenase 3, and both cleave type I collagen fibrils at a neutral $\mathrm{pH}(50,51)$. Cortisol increases the synthesis of collagenase 3 by post-transcriptional mechanisms, regulating specific cytosolic RNA binding proteins, and their binding to specific RNA sequences (52).

One of the most typical features of GIO is the large inter-individual variability in its clinical presentation and severity, the cause of which is yet to be fully understood in both in exogenous and endogenous hypercortisolism. Individual susceptibility to GCs varies considerably and may be explained by differences in the absorption, distribution or metabolism of the steroid molecule, or in the number and affinity of GC receptors or their nuclear cofactors (53, 54). Clinical and in vitro studies propose a potential role of polymorphisms of the GC receptor gene not only as cause for GC sensitivity in patients with inflammatory disorders $(14,54)$, but also as a regulator of differences in BMD and body composition (55).

An attractive explanation to account for differences in skeletal susceptibility to GCs has been identified in the past decade and is related to a peripheral enzyme system of $11 \beta$-hydroxysteroid dehydrogenases $(11 \beta$ HSD), which regulates the interconversion of the inactive hormone (cortisone) into the active hormone (cortisol) (53).

Therefore, this enzyme system plays a crucial role in the regulation of GC activity (56). Two distinct enzymes have been described in humans: type 1 and type 2 $11 \beta$-hydroxysteroid dehydrogenase $(11 \beta$ HSD).

Type $211 \beta$-HSD is expressed in tissues with high concentrations of GC receptors, such as the liver and the adipose tissue, and acts as an inactivating enzyme by converting cortisol into cortisone (56). By contrast, type $111 \beta$-HSD is primarily a GC activator, converting cortisone into cortisol.

Type $111 \beta$-HSD type 1 also favors the synthesis of active GCs in osteoblasts, affecting their proliferation and differentiation, and is widely expressed in target tissues of GC action (56).

The activity of type $111 \beta$-HSD and therefore its ability to generate cortisol from cortisone in human osteoblasts is stimulated by proinflammatory cytokines and exogenous GCs themselves (57).

An increase in the activity of type $111 \beta$ HSD is also enhanced by aging, providing a pathogenic explanation for the markedly enhanced GC effects in the skeleton of elderly subjects (56). 


\section{MANAGEMENT OF GLUCOCORTICOID-INDUCED OSTEOPOROSIS}

When a patient starts a GC treatment which is intended to last at least 3 months, adequate prevention measures against fractures need to be adopted. The same applies to patients already on GCs. Several clinical trials have assessed the effect of bisphosphonates and teriparatide on BMD and fracture risk in patients on GC therapy. Alendronate and risedronate, two biphosponates, have shown to increase BMD and reduce vertebral fracture risk in GC receivers (58-61). Ibandonate, another bisphosphonate, given once monthly, has increased BMD (62).

The zoledronic acid, a bisphosphonate administered in a single annual dose, has shown to increase BMD more than oral risedronate taken daily (63). Lastly teriparatide, the active 1-34 site of the parathyroid hormone, has proven superior to alendronate (64). However, despite the well-known risk of fractures with GC use and the demonstrated efficacy of these agents in preventing bone loss and fracture, many patients do not receive any such treatment $(65,66)$.

Various guidelines for GIO stress the importance of initiating an anti-osteoporosis prophylaxis in patients receiving long-term GC therapy $(67,68)$.

The first step in the prevention process is to encourage all patients receiving GCs to modify their lifestyle, although the evidence of effects of this strategy on fracture risk is weak. In any case adequate levels of dietary calcium intake, adequate exercise, good nutrition, and maintenance of a normal body weight should be encouraged, whereas smoking and alcohol abuse should be avoided. Also an assessment of the risk of falls is recommended and should be accompanied by advice on how to reduce it. Furthermore, the dose of GCs should be periodically reviewed and kept to a minimum. Alternative routes of administration (e.g. topical, inhaled) or formulations (e.g. budesonide) may be considered, and in some situations, the use of alternative immunosuppressive agents may enable reduction in the dose of GCs. There is an almost universal agreement that daily calcium intake (supplement plus oral intake) should be in the order of 1200-1500 mg, and that vitamin D supplementation should be sufficient to achieve therapeutic levels of 25-hydroxyvitamin D or dosage of 800$1000 \mathrm{IU} /$ day $(67,68)$.

Ideally, the timing of the pharmacological anti-osteoporotic intervention in GIO should be based on the individual absolute risk of fracture. The World Health Organization (WHO) developed the FRAX ${ }^{\circledR}$ computer-based fracture risk-assessment tool (http://www.shef.ac.uk/FRAX) to calculate a 10-year fracture probability starting from clinical risk factors with or without BMD testing $(69,70)$.

This risk-assessment tool provides estimates of fracture probability in individuals receiving $\mathrm{GC}$ doses of 2.5-7.5 mg/day, whereas the underlying algorithm can be adjusted according to the GC dose defined in terms of prednisolone-equivalent doses (71). For a low-dose exposure $(<2.5 \mathrm{mg} /$ day prednisolone equivalent) the probability of a major fracture may be downsized, depending on age, whereas with high doses $(\geq 7.5 \mathrm{mg} /$ day $)$ the probabilities fractures can be increased (71).

Thresholds for cost-effectiveness have been developed on the basis of economic assumptions that are country-specific. In the United States, the National Osteoporosis Foundation recommends a drug therapy if the 10-year absolute risk of a major osteoporotic fracture of the hip, spine (clinical, not radiographic), wrist, or humerus is greater than $20 \%$ or if the risk of hip fracture is greater than $3 \%(72)$.

Various guidelines for GIO stress the importance of initiating an anti-osteoporosis prophylaxis in patients receiving chronic GC therapy $(67,68)$. The most recent (2010) recommendations from the American College of Rheumatology (ACR) are stratified by GC dose and fracture risk based on FRAX calculations. For postmenopausal women and men aged 50 and older, they recommend that low- and medium-risk patients (FRAX 10-year risk of a major fracture $<10$ and $10-20 \%$, respec- 
tively) should be treated if their GC dose is $\geq 7.5 \mathrm{mg} /$ day and GC use is expected to last or has already lasted at least 3 months. Medium-risk patients (FRAX 10-20\%) should be treated even if their GC daily dose is $<7.5 \mathrm{mg}$. High-risk patients (FRAX $>20 \%$ ) should be treated for any duration and dose of GCs (67).

For premenopausal women and men younger than 50 , the decision is based on previous fractures. For patients who have not had previous fractures, data was considered too limited to issue a recommendation, whereas in premenopausal women with no childbearing potential who have had a fracture, treatment is indicated if the patient has received GCs at any dose for longer than 3 months, or if the GC dose is $\geq 7.5 \mathrm{mg}$ /day for 1 to 3 months, or even if the dose is $\geq 5 \mathrm{mg} / \mathrm{day}$, even though in this case only alendronate or risedronate are recommended.

Lastly, in premenopausal women with childbearing potential who have had a fracture, there are further complexities to consider, given the potential fetal toxicity of bisphosphonates. In short-term GC therapy at any dose and for a therapy $>3$ months at less than $7.5 \mathrm{mg} / \mathrm{day}$, no consensus has yet been reached by the ACR panel of experts about whether to initiate treatment or not. For therapies lasting $>3$-month at a dose of $\geq 7.5 \mathrm{mg} /$ day, treatment is recommended, avoiding the use of zoledronate based on the long half-life of the drug and concern for fetal toxicity (67).

A joint Guideline Working Group of the International Osteoporosis Foundation (IOF) and the European Calcified Tissue Society (ECTS) has recently published a framework for the development of national guidelines for the management of GIO (68). The IOF-ECTS recommends that, in postmenopausal women and men aged $\geq 50$ years exposed to $\geq 3$ months of oral GCs, a decision should be made on whether to consider treatment directly or to assess risk with adjusted FRAX (with or without BMD testing). This decision should be based on the history of the fracture, age ( $\geq 70$ years), and GC dose $(\geq 7.5 \mathrm{mg} /$ day $)$. Intervention thresholds based on FRAX will also depend on the country. In premenopausal women and men aged $<50$ years exposed to $\geq 3$ months of oral GC, treatment should be considered in patients with prior fracture. Treatment decisions in individuals with no prior fracture should be based on clinical judgment. In addition, it is recommended that all individuals receiving GC therapy should be counseled as to the risks of treatment.

General measures (e.g., good nutrition and regular weight-bearing exercise) should be taken, and patients should be monitored as appropriate (Tab. I) (68).

Bisphosphonates are considered first-line options for GIO (73). Randomized, placebo-controlled trials have shown that alendronate, risedronate, and zoledronic acid are effective for this indication and reduce the risk of vertebral but not hip fractures $(60,63,74)$.

More recently, once-monthly oral ibandronate offered significant improvement in bone mineral density in postmenopausal women treated with GCs for inflammatory rheumatic disease in a 12 month, randomized, double-blind, placebo-controlled trial (62). The evidence for bisphospho-

Table I - General measures and recommendations in the management of glucocorticoid-induced osteoporosis.

\begin{tabular}{l} 
- General measures \\
- Glucocorticoid-sparing therapy: reduce \\
- Consider alternative route of glucocorticoid \\
administration \\
- Recommend good nutritional habits, especially \\
in relation to calcium and vitamin D \\
- Recommend regular weight-bearing exercise \\
- Avoid tobacco use and alcohol abuse \\
- Assess fall risk and advise accordingly \\
\hline Monitoring recommendations during \\
glucocorticoid therapy \\
- Assess compliance to therapy, including use \\
of calcium and vitamin D \\
- If a vertebral fracture is suspected, assess by X-ray \\
or DXA \\
- Measure height annually and BMD at appropriate \\
intervals (especially in patients on high \\
glucocorticoid doses) \\
- Measure serum P1NP after 3 months from the \\
beginning of teriparatide therapy \\
DXA, dual X-ray absorptiometry; BMD, body mass \\
density.
\end{tabular}


nate treatment in GIO is not as strong as in postmenopausal osteoporosis, because the primary end point in the GC treatment trials was BMD rather than fracture, and as explained by the current knowledge in the field of pathophysiology - GCs increase fracture incidence in a way that is partly independent of BMD. In addition, most studies have only lasted 12-18 months and were conducted on insufficient numbers of patients to be able to identify any difference in the incidence of hip fractures.

An advantage of oral bisphosphonates is that they can be stopped, if GCs are discontinued, but compliance with oral formulations is poor.

Annual infusions of zoledronic acid can certainly solve the compliance problem and provide rapid skeletal protection, if GC therapy has already lasted $>90$ days. In this case, there may not be time to wait for the delayed protective effects of oral bisphosphonates, because of their very low oral absorption and lower potency compared with zoledronic acid. Since a substantial BMD loss occurs in patients who discontinue bisphosphonates, while receiving GCs, it is recommended to continue the bisphosphonate treatment as long as the GC treatment lasts.

All bisphosphonates used for the treatment of GIO require caution, if the patient could potentially be pregnant, due to its long half-life. This is particularly true for the zoledronic acid (67).

An alternative GIO treatment is teriparatide, a recombinant human parathyroid hormone (1-34). In an 18-month randomized, double-blind, placebo-controlled trial, teriparatide increased spinal BMD faster and to a greater extent than alendronate and also reduced vertebral fractures (75).

Teriparatide represents a particularly rational approach to GIO, because it counters some fundamental aspects of its pathophysiology, such as the expected GC-induced increase in osteoblast and osteocyte apoptosis and the decrease in the number of osteoblasts. The decreased osteoblast apoptosis leads to an increase in bone formation, while the decreased osteocyte apoptosis is associated with a preservation of bone strength (76). Another potential treatment option is denosumab, a humanized monoclonal antibody to RANKL approved for the prevention of vertebral, nonvertebral, and hip fractures in women with postmenopausal osteoporosis, but not yet for GIO. In a randomized, double-blind, placebo-controlled trial of denosumab in patients with rheumatoid arthritis receiving less than 15 $\mathrm{mg}$ /day of prednisone and methotrexate or methotrexate alone, denosumab reported similar effects in both groups in terms of BMD of the spine and the hip (77). Denosumab may be considered for GC-treated patients with renal failure who are not candidates for bisphosphonates or teriparatide. The ease of administration via subcutaneous injections every 6 months may increase compliance. In patients with GIO, if pain deriving from fractured vertebrae is significant, persistent and resistant to conventional therapy, vertebroplasty and kyphoplasty may be indicated. However, increased fractures in the adjacent vertebrae have been reported, suggesting that prudence should be used before recommending this kind of procedure in these patients (78).

\section{REFERENCES}

1. Mazzantini M, Talarico R, Doveri M, Consensi A, Cazzato M, Bazzichi L, et al. Incident comorbidity among patients with rheumatoid arthritis treated or not with low-dose glucocorticoids: a retrospective study. J Rheumatol. 2010; 37: 2232-6.

2. Kanis JA, Johansson H, Oden A, Johnell O, de Laet C, Melton III LJ, et al. A meta-analysis of prior corticosteroid use and fracture risk. J Bone Miner Res. 2004; 19: 893-9.

3. van Staa TP, Leufkens HG, Cooper C. The epidemiology of corticosteroid-induced osteoporosis: a meta-analysis. Osteoporos Int. 2002; 13: 777-87.

4. Natsui K, Tanaka K, Suda M, Yasoda A, Sakuma Y, Ozasa A, et al. High-dose glucocorticoid treatment induces rapid loss of trabecular bone mineral density and lean body mass. Osteoporos Int. 2006; 17: 105-8.

5. Adachi JD, Saag KG, Delmas PD, Liberman UA, Emkey RD, Seeman E, et al. Two-year effects of alendronate on bone mineral density and vertebral fracture in patients receiving glucocorticoids: a randomized, double-blind, placebo-controlled extension trial. Arthritis Rheum. 2001; 44: 202-11. 
6. Cohen S, Levy RM, Keller M, Boling E, Emkey RD, Greenwald M, et al. Risedronate therapy prevents corticosteroid-induced bone loss: a twelve-month, multicenter, randomized, double-blind, placebo-controlled, parallel-group study. Arthritis Rheum. 1999; 42: 2309-18.

7. Cooper C, Coupland C, Mitchell M. Rheumatoid arthritis, corticosteroid therapy and hip fracture. Ann Rheum Dis. 1995; 54: 49-52.

8. van Staa TP, Geusens P, Pols HA, de Laet C, Leufkens HG, Cooper C. A simple score for estimating the long-term risk of fracture in patients using oral glucocorticoids. QJM. 2005; 98: 191-8.

9. van Staa TP. The pathogenesis, epidemiology and management of glucocorticoid-induced osteoporosis. Calcif Tissue Int. 2006; 79: 12937.

10. Lems WF. Bisphosphonates and glucocorticoids: effects on bone quality. Arthritis Rheum. 2007; 56: 3518-22.

11. Mazziotti G, Angeli A, Bilezikian JP, Canalis E, Giustina A. Glucocorticoid-induced osteoporosis: an update. Trends Endocrinol Metab. 2206; 17: 144-9.

12. Canalis E, Mazziotti G, Giustina A, Bilezikian JP. Glucocorticoid-induced osteoporosis: pathophysiology and therapy. Osteoporos Int. 2007; 18: 1319-28.

13. Toth M, Grossman A. Glucocorticoid-induced osteoporosis: lesson's from Cushing's syndrome. Clin Endocrinol. 2013: 79: 1-11.

14. Hofbauer LC, Rauner M. Minireview: Live and let die: molecular effects of glucocorticoids on bone cells. Mol Endocrinol. 2009; 23: $1525-31$.

15. Davidson ZE, Walker KZ, Truby H. Do glucocorticoids alter vitamin D status? A systematic review with meta-analyses of observational studies. J Clin Endocrinol Metab. 2012; 97 : 738-44.

16. Holick MF, Binkley NC, Bischoff-Ferrari HA, Gordon CM, Hanley DA, Heaney RP, et al. Evaluation, treatment, and prevention of vitamin D deficiency: an Endocrine Society Clinical Practice Guideline. J Clin Endocrinol Metab. 2011; 96: 1911-30.

17. Avioli LV, Birge SJ, Lee SW. Effects of prednisone on vitamin D metabolism in man. J Clin Endocrinol Metab. 1968; 28: 1341-46.

18. Zhou C, Assem M, Tay JC, Watkins PB, Blumberg B, Schuetz EG, et al. Steroid and xenobiotic receptor and vitamin $\mathrm{D}$ receptors crosstalks mediats CYP24 expression and drug-induced osteomalacia. J Clin Invest. 2006; 116: 1703-12.

19. Wortsman J, Matsuuoka LY, Chen TC, Lu Z, Holick MF. Decreased bioavailability of vitamin D in obesity. Am J Clin Nutr. 2000: 72: 690-3.

20. Weinstein RS. Glucocoticoid-induced bone disease. N Engl J Med. 2011; 365: 62-70.

21. Tauchmanova L, Pivonello R, De Martino MC, Rusciano A, De Leo M, Ruosi C, et al. Effects of sex steroids on bone in women with subclinical or overt endogenous hupercortisolism. Eur J Endocrinol. 2007; 157: 359-66.

22. Pivonello R, De Leo M, Vitale P, Cozzolino A, Simeoli C, De Martino MC, et al. Pathophysiology of diabetes mellitus in Cushing's syndrome. Neuroendocrinol. 2010; 92: 77-81.

23. Thrailkill KM, Lumkin CK Jr, Bunn RC, Kemp SF, Fowlkes JL. Is insulin an anabolic agent in bone? Dissecting the diabetic bone for clues. Am J Phys Endocrinol Metab. 2005; 289: E735-45.

24. Giustina A, Wehrenberg WB. The role of glucocorticoids in the regulation of growth hormone secretion. Mechanism and clinical significance. Trends Endocrinol Metab. 2002; 8: 306-11.

25. Malerba M, Bossoni S, Radaeli A, Mori E, Bonadonna S, Giustina A, et al. Growth hormone response to growth hormone-releasing hormone is reduced in adult asthmatic patients receiving long-term inhaled corticosteroid treatment. Chest. 2005; 127: 515-21.

26. Delany AM, Durant D, Canalis E. Glucocorticoid suppression of IGF I transcription in osteoblasts. Mol Endocrinol. 2001; 15: 1781-9.

27. Compston J. Management of glucocorticoidinduced osteoporosis. Nat Rev Rheumatol. 2012; 6: 82-8.

28. Liu Y, Porta A, Peng X, Gengaro K, Cunningham EB, Li H, et al. Prevention of glucocorticoid-induced apoptosis in osteocytes and osteoblasts by calbindin-D28K. J Bone Miner Res. 2004; 19: 479-90.

29. Thornberry NA, Labeznik Y. Caspases: enemies within. Science. 1998; 281: 1312-6.

30. Shi XM, Blair HC, Yang X, McDonald JM, Cao X. Tandem repeat of C/EBP binding sites mediates PPAR $\gamma 2$ gene transcription in glucocorticoid-induced adipocyte differentiation. J Cell Biochem. 2000; 76: 518-27.

31. Zhang W, Yang N, Shi XM. Regulation of mesenchymal stem cell osteogenic differentiation by glucocorticoid-induced leucine zipper. J Biol Chem. 2008; 283: 4723-29.

32. Ohnaka K, Tanabe M, Kawate H, Nawata H, Takayanagi R. Glucocorticoid suppresses the canonical Wnt signal in cultured human osteoblasts. Biochem Biophys Res Commun. 2005; 329: 177-81.

33. Smith E, Frenkel B. Glucocorticoids inhibit the transcriptional activity of LEF/TCF in differentiating osteoblasts in a glycogen synthase kinase-3-dependent and-independent manner. J Biol Chem. 2005; 280: 2388-94.

34. Krishnan V, Bryant HU, MacDougald OA. Regulation of bone mass by Wny signaling. J Clin Invest. 2006; 116: 1202-9.

35. Yao W, Cheng Z, Busse C, Pham A, Nakamura $\mathrm{MC}$, Lane NE. Glucocorticoid excess in mice 
results in early activation of osteoclastogenesis and adipogenesis and prolonged suppression of osteogenesis. Arthritis Rheum. 2008; 58: 1674-86.

36. Hayashi K, Yamaguchi T, Yano S, Kanazawa I, Yamauchi M, Yamamoto M, et al. BMP/Wnt antagonists are upregulated by dexamethasone in osteoblasts and reversed by alendronate and PTH: potential therapeutic targets for glucocorticoid-induced osteoporosis. Biochem Biophys Res Commun. 2009; 379: 261-6.

37. Wang FS, Ko JY, Yeh DW, Ke HC, Wu HL. Modulation of Dickkopf-1 attenuates glucocorticoid induction of osteoblast apoptosis, adipocytic differentiation, and bone mass loss. Endocrinology. 2008; 149: 1793-801.

38. Den Uyl, Bultink IE, Lems WF. Advances in glucocorticoid-induced osteoporosis. Curr Rheumatol Rep. 2011; 13: 233-40.

39. Almeida M, Han L, Ambrogini E, Weinstein RS, Manolagas S. Glucocorticoids and tumor necrosis factor a increase oxidatibe stress and suppress Wnt signaling in osteoblasts. J Biochem Chem. 2011; 286: 44326-35.

40. Manolagas S. From estrogen-centric to aging and oxidative stress: a revise perspective o the pathogenesis of osteoporosis. Endocr Rev. 2010; 31: 266-300.

41. Jilka RL, Almeida M, Amdrogini E, Han L, Roberson PK, Weinstein RS, et al. Decreased oxidative stress and greater bone anabolism in the aged, when compared to the young, murine skeleton with parathyroid hormone administration. Aging Cell. 2010; 9: 851-67.

42. Weinstein RS, Jilka RL, Parfitt AM, Manolagas SC. Inhibition of osteoblastogenesis and promotion of apoptosis of osteoblasts and osteocyets by glucocoticoids: potential mechanism of their deleterious effects on bone. $\mathrm{J}$ Clin Invest. 1998; 102: 274-82.

43. Bonewald LF. The amazing osteocyte. J Bone Miner Res. 2011; 26: 229-38.

44. O'Brien CA, Jia D, Plotkin LI, Bellido T, Powers CC, Stewart SA, et al. Glucocorticoids act directly on osteoblasts and osteocytes to induce their apoptosis and reduce bone formation and strength. Endocrinology. 2004; 145: 1835-41.

45. Weinstein RS, Wan C, Liu Q, Wang Y, Almeida M, O'Brien CA, et al. Endogenous glucocorticoids decrease skeletal angiogenesis, vascularity, hydration, and strength in aged mice. Aging Cell. 2010; 9: 147-61.

46. Hofbauer LC, Gori F, Riggs BL, Lacey DL, Dunstan CR, Spelsberg TC, et al. Stimulation of osteoprotegerin ligand and inhibition of osteoprotegerin production by glucocorticoids in human osteoblastic lineage cells: potential paracrine mechanism of glucocorticoid-induced osteoporosis. Endocrinology. 1999; 140: 4382-9.

47. Rubin J, Biskobing DM, Jadhav, Fan D, Nanes
MS, Perkins S, et al. Dexamethasone promotes expression of membrane-bound macrophage colony-stimulating factors in murine osteoblast-like cells. Endocrinology. 1998; 139: 1006-12.

48. Dovio A, Perazzolo L, Saba L, Termine A, Capobianco M, Bertolotto A, et al. High-dose glucocorticoids increase serum levels of soluble IL-6 receptor alpha and its ratio to soluble gp130: an additional mechanism for early increased bone resorption. Eur J Endocrinol. 2006; 154: 745-51.

49. Takuma A, Kaneda T, Sato T, Ninomiya S, Kumegawa M, Hakeda Y. Dexamethasone enhances osteoclast formation synergistically with transforming growth factor-beta by stimulating the priming of osteoclast progenitors for differentiation into osteoclasts. J Biol Chem. 2003; 278: 44667-74.

50. Knauper V, Will H, Lopez-Otin C, Smith B, Atkinson SJ, Stanton H, et al. Cellular mechanisms for human procollagenase-3 activation. J Biol Chem. 1996; 271: 17124-31.

51. Freje JMP, Diez-Itza I, Balbin M, et al. Molecular cloning and expression of collagenase 3 , a novel human matrix metalloproteinase produced by breast carcinomas. J Biol Chem. 1994; 269: 16766-73.

52. Delany AM, Jeffrey JJ, Rydziel S, Canalis E. Cortisol increases interstitial collagenase expression in osteoblasts by post-transcriptional mechanism. J Biol Chem. 1995; 270: 2660712.

53. Cooper MS. Sensitivity of bone to glucocorticoids. Clin Sci. 2004; 107: 11-23.

54. Barnes PJ. Glucocorticoids: current and future directions. Br J Pharmacol. 2011; 163: 29-43.

55. van Rossum EF, Voorhoeve PG, te Velde SJ, Koper JW, Delemarre-van de Waal HA, Kemper HC, et al. The ER22/23EK polymorphism in the glucocorticoid receptor gene is associated with a beneficial body composition and muscle strength in young adults. J Clin Endocrinol Metab. 2004; 89: 4004-9.

56. Draper N, Stewart PM. 11 $\beta$-hydroxysteroid dehydrogenase and the pre-receptor regulation of corticosteroid hormone action. J Endocrinol. 2005; 186: 251-71.

57. Buttgereit F, Zhou H, Seibel M. Arthritis and endogenous glucocorticoids: the emerging role of the 11 $\beta$-HSD enzymes. Ann Rheum Dis. 2008; 67: 1201-3.

58. Saag KG, Emkey R, Schnitzer TJ, Brown JP, Hawkins F, Goemaere S, et al. Alendronate for the prevention and treatment of glucocorticoid-induced osteoporosis. Glucocorticoid-Induced Osteoporosis Intervention Study Group. N Engl J Med. 1998; 339: 292-9.

59. Cohen S, Levy RM, Keller M, Boling E, Emkey RD, Greenwald M, et al. Risedronate therapy prevents corticosteroid-induced bone loss: a twelve-month, multicenter, randomi- 
zed, double-blind, placebo-controlled, parallel-group study. Arthritis Rheum. 1999; 42: 2309-18.

60. Reid DM, Hughes RA, Laan RF, Sacco-Gibson NA, Wenderoth DH, Adami S, et al. Efficacy and safety of daily risedronate in the treatment of corticosteroid-induced osteoporosis in men and women: a randomized trial. European Corticosteroid-Induced Osteoporosis Treatment Study. J Bone Miner Res. 2000; 15: 1006-13.

61. Wallach S, Cohen S, Reid DM, Hughes RA, Hosking DJ, Laan RF, et al. Effects of risedronate treatment on bone density and vertebral fracture in patients on corticosteroid therapy. Calcif Tissue Int. 2000; 67: 277-85.

62. Hakala M, Kröger H, Valleala H, HienonenKempas T, Lehtonen-Veromaa M, Heikkinen $\mathrm{J}$, et al. Once-monthly oral ibandronate provides significant improvement in bone mineral density in postmenopausal women treated with glucocorticoids for inflammatory rheumatic diseases: a 12-month, randomized, double-blind, placebo-controlled trial. Scand J Rheumatol. 2012; 41: 260-6.

63. Reid DM, Devogelaer JP, Saag K, Roux C, Lau CS, Reginster JY, et al. Zoledronic acid and risedronate in the prevention and treatment of glucocorticoid-induced osteoporosis (HORIZON): a multicentre, double-blind, double-dummy, randomised controlled trial. Lancet. 2009; 373: 1253-63.

64. Saag KG, Shane E, Boonen S, Marín F, Donley DW, Taylor KA, et al. Teriparatide or alendronate in glucocorticoid-induced osteoporosis. N Engl J Med. 2007; 357: 2028-39.

65. Curtis JR, Westfall AO, Allison JJ, Becker A, Casebeer L, Freeman A, et al. Longitudinal patterns in the prevention of osteoporosis in glucocorticoid-treated patients. Arthritis Rheum. 2005; 52: 2485-94.

66. Feldstein AC, Elmer PJ, Nichols GA, Herson M. Practice patterns in patients at risk for glucocorticoid-induced osteoporosis. Osteoporos Int. 2005; 16: 2168-74.

67. Grossman JM, Gordon R, Ranganath VK, Deal C, Caplan L, Chen W, et al. American College of Rheumatology 2010 recommendations for the prevention and treatment of glucocorticoid-induced osteoporosis. Arthritis Care Res. 2010; 62: 1515-26.

68. Lekawasam S, Adachi JD, Agnusdei D, Bilezikian J, Boonen S, Borgström F, et al. A fra- mework for the development of guidelines for the management of glucocorticoid-induced osteoporosis. Osteoporos Int. 2012; 23: 2257-76.

69. Kanis JA, Johnell O, Oden A, Johansson H, McCloskey E. FRAX and the assessment of fracture probability in men and women from the UK. Osteoporos Int. 2008; 19: 385-97.

70. Kanis JA, McCloskey EV, Johansson H, Strom O, Borgstrom F, Oden A. Case finding for the management of osteoporosis with FRAX-assessment and intervention thresholds for the UK. Osteoporos Int. 2008; 19: 1395-408.

71. Kanis JA, Johansson H, Oden A, McCloskey EV. Guidance for the adjustment of FRAX according to the dose of glucocorticoids. Osteoporos Int. 2011; 22: 809-16.

72. National Osteoporosis Foundation. Clinician's guide to prevention and treatment of osteoporosis. Washington, DC, National Osteoporosis Foundation, 2010. http://nof.org/files/nof/public/content/file/344/upload/159.pdf

73. Weinstein RS. Clinical practice: glucocorticoid-induced bone disease. N Engl J Med. 2011; 365: 62-70.

74. Adachi JD, Saag KG, Delmas PD, Liberman UA, Emkey RD, Seeman E, et al. Two-year effects of alendronate on bone mineral density and vertebral fracture in patients receiving glucocorticoids: a randomized, double-blind, placebo-controlled extension trial. Arthritis Rheum. 2001; 44: 202-11.

75. Saag KG, Shane E, Boonen S, Marín F, Donley DW, Taylor KA, et al. Teriparatide or alendronate in glucocorticoid-induced osteoporosis. N Engl J Med. 2007; 357: 2028-39.

76. Weinstein RS, Jilka RJ, Roberson PK, Almeida M, Roberson PK, Manolagas SC. Intermittent parathyroid hormone administration prevents glucocorticoid-induced osteoblast and osteocyte apoptosis, decreased bone formation, and reduced bone strength in mice. Endocrinology. 2010; 151: 2641-9.

77. Dore RK, Cohen SB, Lane NE, Palmer W, Shergy W, Zhou L, et al. Effects of denosumab on bone mineral density and bone turnover in patients with rheumatoid arthritis receiving concurrent glucocorticoids or bisphosphonates. Ann Rheum Dis. 2010; 69: 872-5.

78. Syed MI, Patel NA, Jan S, Shaikh A, Grunden B, Morar K. Symptomatic refractures after vertebroplasty in patients with steroid-induced osteoporosis. AJNR Am J Neuroradiol. 2006; 27: 1938-43. 